\title{
Barriers and Community Land Trust's Strategies in The Preservation of Affordable Housing
}

\author{
Mina Elsie Louis Udom* Weje, Ikezam Innocent, Ph.D. \\ Department of Urban and Regional Planning, Faculty of Environmental Sciences, Rivers State University
}

\begin{abstract}
This study investigated housing affordability in St Minver and Brambleside Community Land Trust, Cornwall, England. The methodology adopted was the qualitative methodology. The study addressed the potential barriers as well as the strategies adopted in the Community Land Trust (CLT) in the preservation of housing affordability. In-depth interviews were carried out on members of the community comprising both home owners and tenants. Findings revealed barriers such as the rigidity and overly stringent bureaucratic structures which oversee and regulate the program, and the desire of landowners to make profit, while CTL's strategies involve increased control over the resale of the houses and an emphasis on the purpose for its development for low-income earners. In conclusion it was stated that it is imperative to address these barriers in line with enabling quick decision making and ensuring the actual gains of the program are made available to its key targets
\end{abstract}

Keywords: Housing affordability, Community Land Trust, House sale restrictions, Bureaucratic regulations

DOI: $10.7176 / \mathrm{JEES} / 9-3-02$

Publication date:March $31^{\text {st }} 2019$

\section{Introduction}

Debates within housing policy on housing affordability has over the last decade become one of the three main foci for housing research within developed countries (Megbolugbe, 1997), including the UK, where there is a shift from a housing policy centered on need to affordability (Whitehead, 1991). Affordable housing has come up to the fore in housing issues, and for UK, the major focus on affordability is tied to income and housing cost ratios where the housing cost is more than 30\% of a household income (Whitehead, 2011; Davis, 1997).

The discourse on affordability is further reflected in the role of urban planning, identified as the tool for securing affordable housing (Whitehead, 2011); but, in reality, the exclusionary zoning planning regulations as applied in the US planning system are seen as a threat to low income households, where developments are beneficial to high income earners through low density housing typologies, creating the need for inclusionary zoning regulations where housing developments are to include some amount of affordable housing (Whitehead, 2011).

Studies carried out in UK and Australia on housing problems, led to reforms in the planning systems to reduce planning barriers in the supply of land and housing (Whitehead, 2011). However, the effect of this outcome is limited, as several researches recently still highlighted the challenges facing affordable housing (Mckee, 2012; Moore, 2014) and have projected the development of a model system aimed at providing access to land leased from non-profit organizations through ownership of buildings or improvements by members or residents of a community in achieving the dream of housing provision known as Community Land Trusts (CLT) (Bagdol, 2013).

Despite efforts in providing affordable housing, through the Affordable Homes program, there is an increasing demand for housing outweighing supply. Recent policy decisions on sale of council and social housing (Inside Housing, 2011) are viewed by Housing Associations as a challenge in affordable housing provision. The focus of study is on the barriers to affordable housing in community land trusts through perspectives of affordable home owners and tenants in local communities, the challenges faced in its operations and the strategies adopted by the CLTs in preserving housing affordability. This is paramount as previous studies (DeFilippis, 1999) have focused on the benefits and successes achieved by CLTs; however, an investigation into the existing barriers is justified on the basis of identifying and addressing the prevailing loopholes which stifle the progress and overall success of the program.

\subsection{Research Objectives}

i. To examine the major barriers in preserving affordable housing provision in St Minver and Brambleside Community Land Trust, Cornwall.

ii. To ascertain CLTs strategies in encouraging the preservation of housing affordability in St Minver and Brambleside Community Land Trust, Cornwall. 


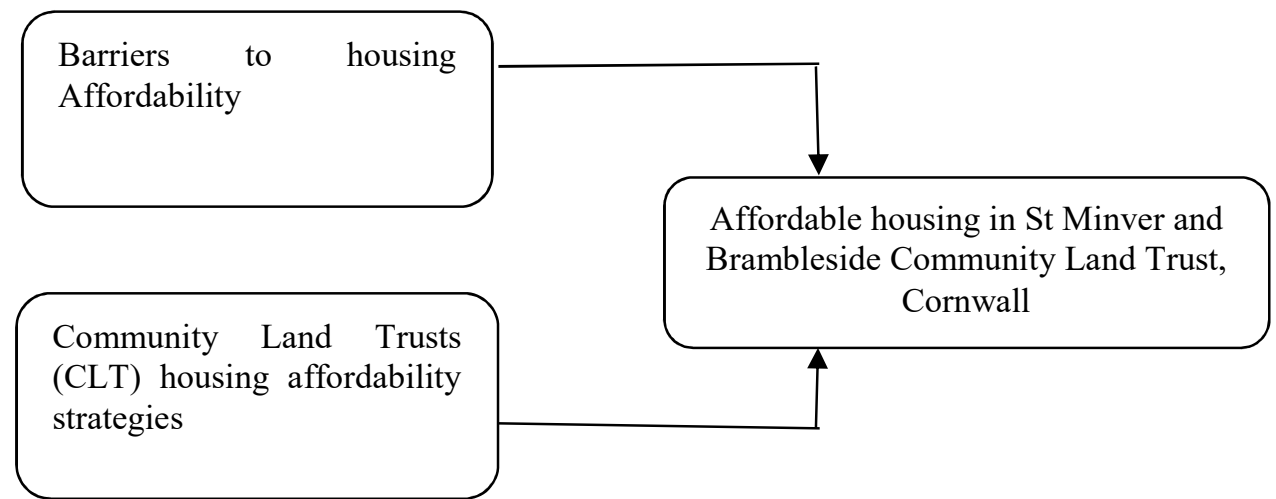

Figure 1: Conceptual framework

\section{Affordable Housing}

The earliest discourse on affordable housing recorded in the US, has evolved over the years from failure and neglect by the federal government of its role in housing provision for low income households, to a lack of prioritization and perception by federal legislators regarding housing need for low income households, a lack of housing initiatives for the low income households in its public housing policy (Martens, 2009), an interest in home ownership beneficial to the middle income and high income earners (Sazama, 2000).

This is a view put forth by Sazama (2000), who in addition, insists that the history of affordable housing is incomplete without the affordable housing cooperatives, which followed the model of the cooperative movement first established in Rochdale, England in 1844 with an underlying principle of capital control through a democratic process. Its relationship with affordable housing is seen as such due to the fact that it provides an alternative that ensures joint ownership of property; empowers the low-moderate-income families and residents to take responsibility for their decisions which impacts on costs and quality of the housing (Sazama, 2000). A further evolution within this period, are the creation of Land Trusts regarded as consumer cooperatives run as non-profit organizations and seen as having recorded better success in the provision of affordable housing.

Affordable housing is regarded as" additional housing units (or bed spaces) provided to specified eligible households whose needs are not met by the market". In the same vein, the US Department of Housing and Urban Development defined "housing as "affordable" to any household, if that household can pay for occupying a unit of "decent quality" without spending more than $30 \%$ of its income for housing" (Downs, 2004). The main reason for the emergence of Community Land Trusts as solutions for affordable housing in cities, is as a result of the fallout of the housing needs of the low income households due to high cost of living and stagnant wages. Evidence on this is based on a study carried out between 2006 and 2010, which showed a $52 \%$ increase over that of the year 2000 within households of the 25 largest metropolitan cities in the US (Miller, 2015). It further argued that short term affordability tenures provided by developers on behalf of councils were short lived as upon expiration, such properties lose their affordability (Miller, 2015).

\section{Community Land Trusts}

A review of literature on the community Land Trust (CLT) model has been espoused by different authors (Moore, 2014; Miller, 2015). However, the most descriptive narrative is a recent review by John Emmaus Davis in his book, "Origins and Evolution of The CLT in the United States" who regarded CLT as a product of ideas, experiments and social movements spanning over two decades. Davis (2014) is equally of the view that CLT is a model cultivated and adopted in cities, towns and suburbs with three distinctive characteristics of ownership, organization and operation. According to Davis (2014), the characteristics of ownership have evolved from municipal ownership of land by a municipal corporation served by trustees to ownership of land by non- profit organizations. In terms of organization, CLTs have evolved from being regarded as planned communities on leased land to community land trusts, due to organizational characteristics of open membership to residents within the area, election into the CLTs' governing board members by the CLT members, and a tripartite governing board membership comprising of representatives of CLT Owners (Davis, 2014). The last key characteristic of the CLT viewed by Davis (2014) in terms of operation is the resale restriction covenants added in the model to ensure permanent affordability. Despite the detailed narrative by Davis (2014), a contrasting view held is that CLTs are fallouts of a model derived out of the Co-operative Land Society System created by Ebenezer Howard following Land Reforms in India in the 1950s and 1960s by the Civil rights movement in Georgia, where American share croppers had access to affordable farmland. (National Assembly for Wales, 2010).

\section{Community Land Trusts in UK}

CLTs are regarded as being in existence prior to the present time due to the garden cities project of Letchworth 
and Welyn (Davis, 2014; Dunn, 2009), which sought to convert urban areas into planned environments due to the chaos in urban areas. The emergence of CLTs in Scotland is based on a land ownership system long in existence, and promoted due to lack of investment in housing, and a reluctance of land sale to individuals for development by the feudal landowners. The Scottish land reforms Act in 2003 was a boost to the CLT as it gave community the right to purchase land (Mckee, 2012). One of the positives of this model in Scotland is the increase in community assets acquisition over the last 25 years and a widespread support for the community in land ownership (Allison, 2014). Another significant positive is the empowerment it provides on land management to the communities through job opportunities and affordable housing (Murray, 2013); equally noted by Murray, (2013) is the economic build up and private enterprise development on land for projects such as renewable energy schemes, infrastructure development and affordable housing especially in communities with declining populations, such as the North Harris Trust with an ownership of 62,00acres of the west coast of Scotland (Murray, 2013).

For the government, CLTs are vehicles in preserving affordable housing, at a time when housing shortages, cuts in spending had stretched local authorities' capacity for funding. In addition, the community right to buy in the localism bill now gives powers to local communities to explore opportunities for affordable housing (DCLG, 2011). There is a further support for its emergence as a timely tool to integrate into local government housing policies due to high cost of living and stagnant wages (Miller, 2015); in addition, it's seen as a better option to counter the short-term affordability tenures provided by developers on behalf of councils. These short-term tenures create loss in affordability upon tenure expiration and conclude that CLTs are adopted models by cities to address housing affordability, but are modified to respond to specific circumstances faced by local opportunities and challenges (Miller, 2015). From planning perspectives, CLTs are regarded as the solution for tackling the most difficult projects in the most distressed neighbourhoods (Peterson, 1996). Distressed neighbourhoods according to Ekstam (2015) are "Neighbourhoods with low incomes, low occupational levels, as well as poor health."

\section{Barriers to affordable housing in Community Land Trusts}

Perception is how we view the world, which determines how we behave toward other people, how we identify our interests, and how we view politics and policies (Tighe, 2010). Tighe gives a further description on perceptions as "the pictures in our heads" and argues that these pictures actually determine how our opinions are formed. Recent researches on sustainability, and communal land ownership have tried to identify the notion of perceptions, linking such with beliefs, feelings and attitudes of individuals, within the context, of communal land ownership based on experiences of the individuals within the communities, likewise barriers are regarded as challenges, conflicts that experienced by communities, in this regard, with respect to communal land ownership, which are a principal feature of Land trusts (Bailey, 2010).

In sustainable development, Lele (1991) is of the view that there is a link between poverty and environmental degradation, and economic growth is deemed to be able to alleviate poverty. Therefore, the provision of affordable housing through CLTs are amongst other strategies adopted by governments to stimulate economic growth through regeneration and ensure high environmental standards such as zero carbon emissions in terms of design standards (Bailey, 2010). In view of the foregoing, the following research questions are put forward:

i. What are the major barriers in preserving housing affordability in St. Minver and Brambleside Community Land Trusts?

ii. What are the CLT's strategies in the preservation of Affordable Housing in St. Minver and Brambleside Community Land Trusts?

\section{Methodology}

6.1 Research Design: This study is designed as a case study as it focuses on Community Land Trusts in St Minver and St. Teath, Brambleside communities in Cornwall. The study adopts the qualitative (idiographic) methodology in its investigation of the perceptions of homeowners with regards to the barriers to affordable housing in community land trusts. This is premised on the nature of the study which draws significantly from the highly subjective feelings and experiences of the target respondents and their unique as well as conscious constructions and interpretations of their life world. This examination therefore utilized in-depth interviews as its primary data collection instrument (Patton, 2002).

6.2 Data Collection: In gathering facts, an empirical investigation was conducted, from data derived through both secondary and primary sources; key stakeholders / partners that have contributed to the affordable housing program of the CLTs; the local authority, Rural Housing Association and the Umbrella Community Land Trust, key personnel in the Community land trusts, CLTs residents( Owners and Tenants), local housing agents involved in CLT properties within St. Minver and Brambleside, Cornwall, England as well as field observation and other research tools.

6.3 Sample Area: The area of case study is the Community Land Trusts in St Minver and St. Teath, Brambleside 
communities in Cornwall, England; for the purpose of data gathering and analysis, in addition, is the local authority, the Cornwall Council, the Cornwall Rural Housing Association as well as the Cornwall Community Land Trusts.

6.4 Respondents: The choice of respondents was based on the identification of key players within these organizations and a selection of home owners within the CLT members. A minimum number of 25 respondents were considered as threshold in the assessment of data saturation and covered a variety of respondents from the identified categories of home owners, tenants of St Minver and Brambleside, key personnel in the Cornwall Rural Housing Association, Cornwall Community Land Trust, the Councilor for St Minver, a board member of St Minver CLT.

\section{Data Results}

This section presents the results for the analysis on the data of the study. It presents a detailed description of the various stages of data, sorting and coding followed by the report.

7.1 Data Preparation and Properties: A total of six (6) initial codes were generated for the study. These codes were used to reduce and categorize the observed themes and relevant responses to the interviews. Thereafter these codes are further linked through the utilization of two (2) axial codes which served as parent codes for the categories of the initial codes. Both (2) axial codes are priori in nature and reflect the research questions of the study. This was done with the intent of maintaining focus on the primary variables and issues of the study (Creswell, 2007).

Table 1: Coding process (initial and axial)

\begin{tabular}{|c|c|c|c|}
\hline \multicolumn{2}{|c|}{ Initial codes } & Axial codes & Research questions \\
\hline i. & Bureaucracy and regulations & Major Barriers & What are the major barriers in preserving \\
\hline ii. & Landowners estimation of site & & housing affordability in St. Minver and \\
\hline & market value & & Brambleside Community Land Trusts? \\
\hline iii. & Unavailability of sites in some & & \\
\hline i. & Check on use of property & CLT's Strategies & What are the CLT's strategies in the preservation \\
\hline ii. & Criteria for occupancy & & of Affordable Housing in St. Minver and \\
\hline iii. & Sale restrictions & & Brambleside Community Land Trusts? \\
\hline
\end{tabular}

Source: Survey Data

Table 1 illustrates the categorization process from initial codes to axial codes based on the theme of the research questions. Each initial code provides a category which represents observed threads on an issue with regards to the interview questions. While the axial codes represent priori labels which serve to link and group the initial codes with regards to the research questions of the study.

7.2 Data Reporting: The data reporting for the study is based on the research questions which provide the primary framework within which the data is structured. Each research question is treated according based on the arguments and opinions of the respondents.

What are the major barriers in preserving housing affordability in St. Minver and Brambleside Community Land Trusts?

The first research question addressed the major barriers experienced in the preservation of housing affordability in the interested communities. The data revealed three main factors which could be considered as the dominant challenges experienced in the preservation of the affordability of the housing projects, these are first, the red tape bureaucracy and regulations which slowed down and in most cases impinged negatively on the housing project, second, the landowners estimation of the actual site market value for the projects and the possibility of greater gain for the sales of their lands, and third, the unavailability of sites due to the unfavorable nature of the sites in most of the communities. These identified factors were thus represented using three codes namely: bureaucracy and regulations, land owner's estimation of market site values, and unavailability of sites in some communities.

The evidence of the study suggested that with regards to the challenges of preserving the affordability of the houses, factors such as: the rigidity of bureaucracy and other related regulations, and the unavailability of land primarily as a result of the high prices of land as a result of the insistence of some landowners at giving them away only at their actual market values, can all be considered as substantial mitigating factors.

What are the CLT's strategies in the preservation of Affordable Housing in St. Minver and Brambleside Community Land Trusts?

The second research question addressed the perception of respondents with regards to the sales restrictions to the provision of affordable housing in the interested areas. Data reveals that three factors are predominant with 
regards to sales restrictions. These are summarized in the following codes: Sales restrictions - which indicated that restrictions were based on issues related to pricing and the affordability of such houses for low income earners; check on use of property - which represents opinions about the check on the intended usage of the property; and criteria for occupancy - which reflects the insistence that the property serves one of the primary the purposes for which it is set up which up which is the provision of housing to low income earners and those who otherwise cannot afford homes of such characteristics.

The evidence generated from the data indicates that the sales restrictions are primarily aimed at first protecting the interest of the categories of people or individuals the houses are built for and secondly to provide a check on the use of the houses. The evidence also suggests that such restrictions are considered necessary in the screening of potential buyers as well as formulation of the resale covenant.

The following summaries are premised on the evidence presented by the results of the analysis on the study of the potential barriers to Affordable Housing and Community Land Trust's strategies in preserving housing affordability as it specifically affects Home Owners in St Minver, England:

i. The major and potential barriers of preserving the affordability of the housing programs are concerned with the rigidity and overly stringent bureaucratic structures which oversee and regulate the program, the desire of landowners to make profit based on the actual market value of the planned sites thereby leading to a scarcity of available sites for the program

ii. The strategies adopted by the CLT in view of preserving housing affordability in St. Minver comprise of increased control over the resale of the houses as a result of the insistence on maintaining affordability, ensuring that the right people who need the houses are actually those who get them and also ensuring that the houses are utilized based on the intent and purpose of reaching out to low-income earners.

\section{Discussion of Findings}

The result of the analysis revealed substantial evidence which links the perceptions of homeowners with regards to the community land trust housing programs to several factors such as key issues which impact on the affordability of housing. These can be considered as reflecting the homeowners' position and feelings towards the housing program and depicts their support or disapproval of various activities and events associated with the housing program. Findings indicated significant challenges experienced by the program, highlighting on factors such as the rigidity and frustrating bureaucratic protocols experienced during the program, the desire by some landowners to make profit from their lands by selling only at the market value for the sites and as the scarcity of sites due to price factors. These posed as significant limitations and mitigated substantially on the progress or activities of the housing program (Miller, 2015).

The findings further revealed that in terms of sales restrictions, homeowners affirm to sales streamlining based on maintaining housing affordability, ensuring the target group of individuals for which the houses were developed actually get them and also ensuring that the houses are not used for other purposes outside the original intent of the design and objective (Mckee, 2012; Dunn, 2009). This implies a tendency for minimal house pricing and resale policies and the support for the well-being and development of various community members.

\section{Conclusion}

In conclusion, the findings of the study provide a basis and premise for the assertions that the barriers of preserving the affordability of the housing programs are premised on three main factors, namely: the red tape bureaucracies and overly rigid regulatory activities of the authorities, the market value estimates of the sites and the unavailability of some sites as a result of their prices. There is therefore a need to address these factors in line with enabling quick decision making and ensuring the actual gains of the program are made available to its key targets. Also, policies should be formulated to further strengthen the sales restrictions placed on the sale and resale of the houses as a way of controlling possible excesses with regards to the usage of the property, so as to maintain its affordability and therefore accessibility to low-income earners and also to ensure its target occupants and groups are given the required opportunities and support to acquire the properties

\section{References}

Allison E. J. W. (2014, May 23rd). Land Reform Review Group Final Report - The Land of Scotland and the Common Good. Retrieved from Scottish Government: http://www.gov.scot/Publications/2014/05/2852

Bagdol, A. (2013). Property Taxes and Community Land Trusts: A Middle Ground*. Texas Law Review, 939-959.

Bailey, N. (2010). Building Sustainable Communities from the Grassroots: How Community Land Trusts can create social sustainablity. In J. A. Tony Manzi, Social Sustainability in Urban Areas: Communities, Connectivity (p. 49). London: Earthscan. Retrieved October 16th, 2016, from HYPERLINK "https://books.google.co.uk/books?hl=en\&lr=\&id=JoCu6Er7c78C\&oi=fnd\&pg=PA49\&dq=perceptions+of +the+barriers+to+Community+Land+Trusts\&ots=hOUdqpavJR\&sig=jlfmgs6_ZzkpBpB_Gjrxsnnxbe4" $\backslash 1$ "v=onepage\&q\&f=false" 
https://books.google.co.uk/books?hl=en\&lr=\&id=JoCu6Er7c78C\&oi=fnd\&pg=PA49\&dq=perceptions + of + the+barriers+to+Community+Land+Trusts\&ots=hOUdqpavJR\&sig=jlfmgs6_ZzkpBpB_Gjrxsnnxbe4\#v=on epage\&q\&f=false

Creswell, J. W. (2007). Qualitative Enquiry and Research Design: Choosing Among Five Approaches. SAGE Publications. London

Davis, S. (1997). Architecture of Affordable Housing. Berkely and Los Angeles, California: University of California Press.

DeFilippis, J. (1999). Alternatives to the "New Urban Politics": finding locality and autonomy in local economic development. Political Geogrraphy, 18(8), 973-990.

DCLG. (2011). Affordable Housing Supply, England 2010-2011 Housing Statistical Release. Retrieved May 23rd, 2016 ,

from https://www.gov.uk/government/uploads/system/uploads/attachment_data/file/6419/20015771.pdf

Downs, A. (2004). Growth Management and Affordable Housing: Do they conflict? Washington D.C: The Brookings Institution Press.

Dunn, E. P. (2009). Perspectives on utilising Community Land Trusts as a vehicle for affordable housing provision. Local Environment, 749-764.

Ekstam, H. (2015). Residential Crowding in a "Distressed" and a "Gentrified" Neighbourhood -Towards an Understanding of Crowding in "Gentrified" Neighbourhoods. Housing, Theory and Society, 429-449

Inside Housing. (2011). Between a Rock and a Hard Place. Retrieved February 19th, 2016, from http://www.insidehousing.co.uk/between-a-rock-and-a-hard-place/6514345.article

Lele, S. M. (1991). Sustainable Development: A Critical review. Retrieved October 13th, 2016, from HYPERLINK

"http://ac.els-cdn.com/0305750X9190197P/1-s2.0-0305750X9190197Pmain.pdf? tid=2dedc31a-9142-11e6-96b9-

00000aab0f26\&acdnat $=1476362590 \quad 2549548642$ ebf51d82cbd3ba6c7aa9fc" http://ac.elscdn.com/0305750X9190197P/1-s2.0-0305750X9190197P-main.pdf? tid=2dedc31a-9142-11e6-96b900000aab0f26\&acdnat $=1476362590 \quad 2549548642$ ebf51d82cbd3ba6c7aa9fc

Martens, B. (2009). A Political History Of Affordable Housing. Journal of Housing and Community Development, 6-12.

Mckee, T. M. (2012). Empowering Local Communities? An International Review of Community Land Trusts. Housing Studies, 27(No. 2), 280-290.

Megbolugbe, P. L. (1997). Housing affordability: Myth or Reality? Sage, 369-392.

Miller, S. R. (2015). Community Land Trusts: Why Now Is the Time to Integrate This Housing Activists' Tool into Local Government Affordable Housing Policies. Journal of Affordable Housing and Community Developemnt Law, 349-371

Moore, D. T. (2014). affordable homes for local communities: The effects and prospects of Community land trusts in England. Centre for Housing Research.

Murray, A. (2013, September 24th). Ownership is key for Scottish Communities. Retrieved from Co-operative News: http://www.thenews.coop/40020/news/business/ownership-key-scottish-communities

National Assembly for Wales. (2010, June). Community Land Trusts. Retrieved from National Assembly for Wales: http://www.assembly.wales/Research\%20Documents/Community\%20Land\%20Trusts\%20-\%20Quick\%20guide -28062010-188743/qg10-0014-English.pdf

Patton, M. Q. (2002) Qualitative Research and Evaluation Methods, Third Edition, Sage Publications, Inc.

Sazama, G. W. (2000). Lessons from the Histoiry of Affordable Housing Cooperatives in the United States: A Case Study in American Affordable Housing Policy. American Journal of Economics and Sociology, 573608

Tighe, J. R. (2010). Public Opinion and Affordable Housing: A review of the Literature. Journal of Planning Literature, 3-17

Whitehead, N. G. (2011). Planning and Affordable Housing in Australia and the UK: A Comparative Perspective. housing Studies, 1193-1214 